\title{
ADMITTANCE CONTROL OF AN ELECTRO-HYDRAULIC SERVO-DRIVE
}

\author{
P. Wos ${ }^{*}$, R. Dindorf ${ }^{* *}$
}

\begin{abstract}
The article describes the possibilities of electro-hydraulic servo-drive control in the admittance system. The principle of admittance control is presented and a method for implementing this kind of control for the servo drive controller has been proposed. Admittance method can be effective when there is a need for exerting precise force. This kind of measure extends the capabilities of control systems which uses only measurement of the displacement.
\end{abstract}

Keywords: admittance control, force control, electro-hydraulic, servo-drive

\section{Introduction}

Control of position in combination with compensation of force load is required for many industrial tasks. We have been dealing with these problems for decades. At this time, a number of mutually different methods and algorithms were created (Peng et al., 2016; Shaer et al., 2017). Each of the proposed methods contains a few advantages and disadvantages, and cannot be used to implement all tasks (Rahmat et al., 2010; Yuan et al., 2017). Particularly drives, that require the coupling of the applied force. It should be emphasized, that the methods of controlling the force position have a high computational complexity that allows for control position and force of the hydraulic cylinder. All control method using feedback from force must take into account the dynamic dependence between the position and reaction force. So the force control is integrally linked with position control (Wos and Dindorf, 2016). At the same time control method must ensure stable behavior of the system for changing the size of loading forces. Therefore, it is difficult to realize the control system that is independent and insensitive to changes in system load parameters (Kheowree and Kuntanapreeda, 2015).

\section{Electro-hydraulic servo control system}

Electro-hydraulic positioning systems are those systems in which changes of position, velocity and acceleration actuator refer to the changes of technological load. In these techniques both proportional valve and servo valve control are used. To control there are used the digital cards and groups of regulators, amplifiers cards, set-point modules as well as sensors and setting units system (Stefanski and Zawarczynski, 2016). In the case where the resistance of technological force and pressure in the chambers of the actuator can be represented as variable state, then we can apply control circuits shown in Fig. 1b. The block diagram of the force control looks like a position control system (Fig. 1a). The difference is when we exchange the position sensor into the force sensor or pressure sensors. The continuous measurement of load power technology is followed to maintain a stable position of the actuator with varying external load. We have to maintain constant pressure in the chamber, which determines its movement (Wos and Dindorf, 2013). Self-compensation occurs when the value of the loading force is known and on that basis the regulator determines the correct signal. The card amplifier of valve control

PhD Piotr Wos, Faculty of Mechatronics and Machine Design, Kielce University of Technology, Kielce, 25-314, Poland, wos@tu.kielce.pl

** Prof. Ryszard Dindorf, Faculty of Mechatronics and Machine Design, Kielce University of Technology, Kielce, 25-314, Poland, dindorf@tu.kielce.pl 
module is cooperating with inductive position measuring system of the slider separator (position control) or module when it is controlled by the voltage (pressure control). This card usually contains standard classical regulators P, PD or PID, a correction of nonlinearity, hysteresis restrictions distributor, steepness of the fall and rise of the control signal, zero offset adjustment (Blasiak et al., 2017).

a)

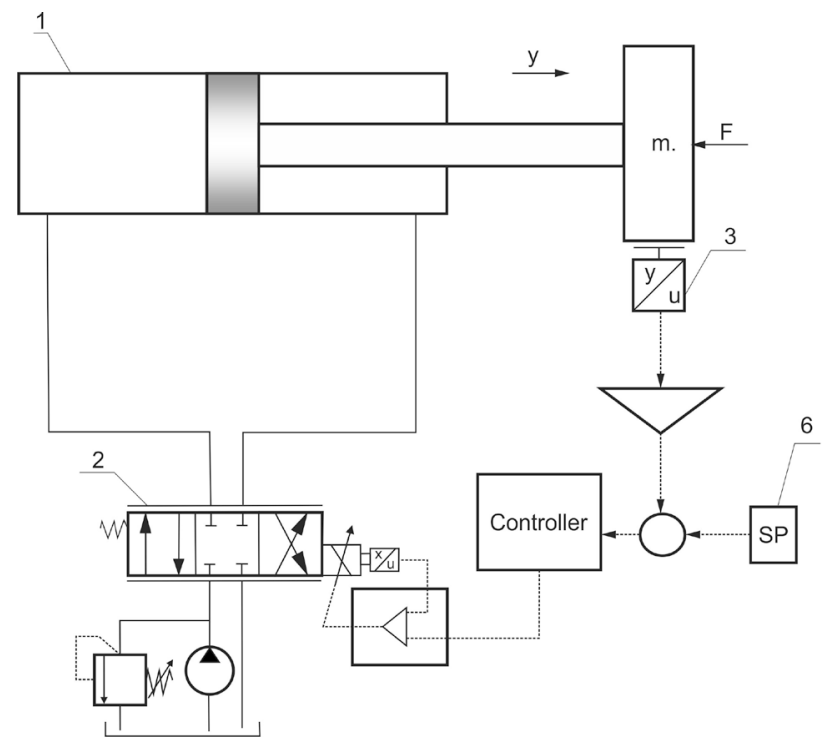

b)

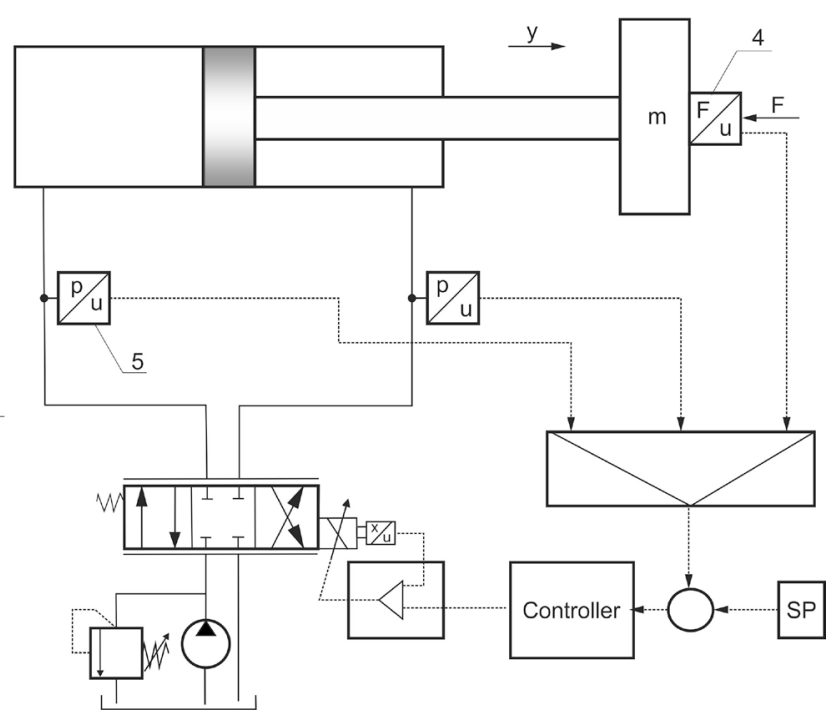

Fig. 1: Position control (a) and force (b) system of the electro-hydraulic servo-drive: 1-hydraulic cylinder, 2 -proportional flow control valve, 3 -position and velocity measuring system, 4 -force sensor, 5 - pressure sensors, 6 - set point generator (SP)

Figure 2 presents view of experimental test-stand.

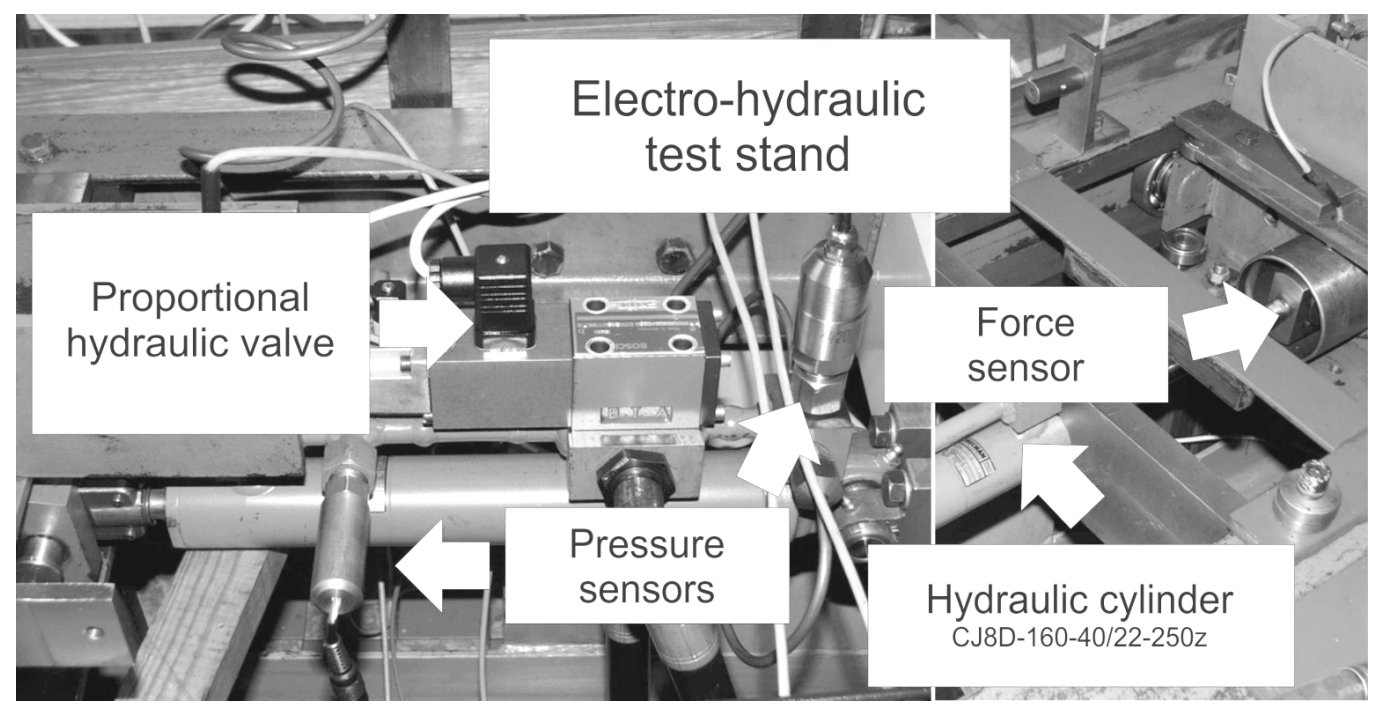

Fig. 2: Test stand

\section{Admittance control}

The theory of control introduces the concepts of admittance control and impedance control (Hogan and Buerger, n.d.; Richardson et al., 2005), which were introduced by analogy of mechanical systems to electric ones. In the admittance, control signal from the force sensor is converted into position signals (velocity) by modifying the operation of the control algorithm (Fernando et al., n.d.; Lee and Newman, 2014). This involves proper correction of the set-point position (velocity) based on the variables of force. This approach gives rise to an external force control loop that is closed around the main control circuit. 


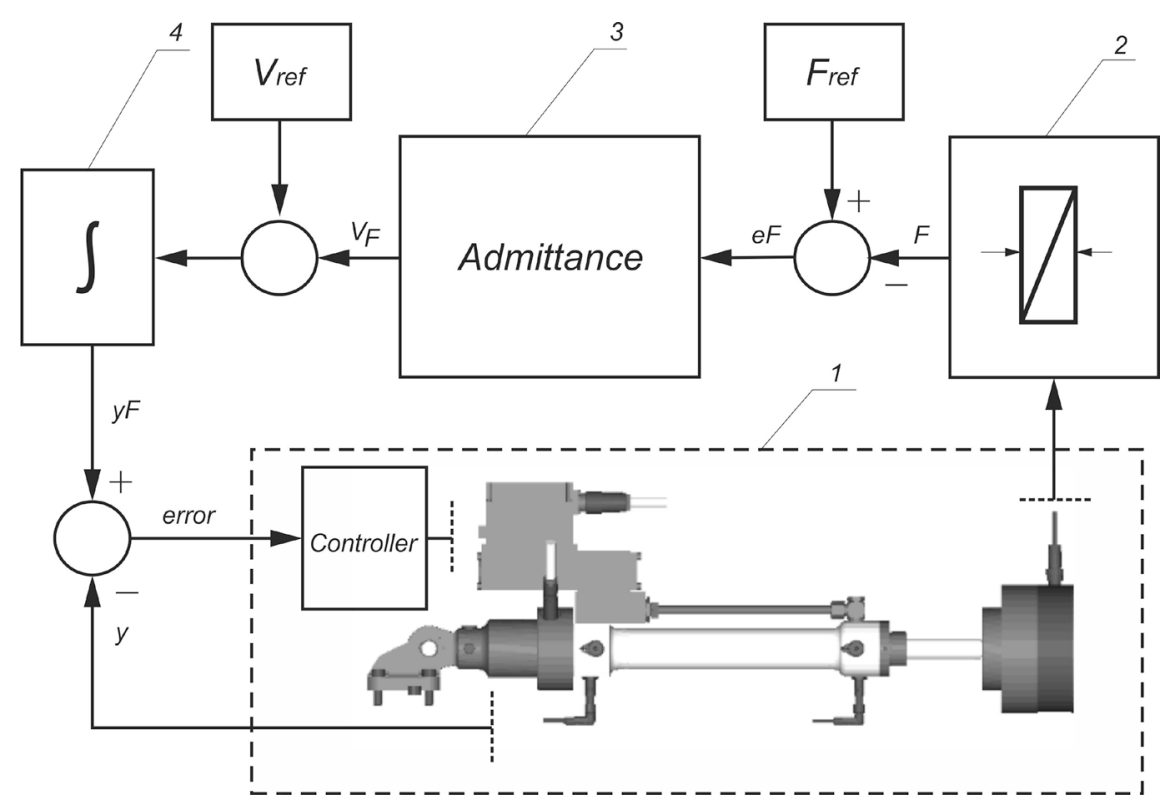

Fig. 3: A block diagram of the admittance control (AC) system: 1 - electro-hydraulic servo-drive, 2 - load sensor, 3 - admittance block, 4 - integrator block

The controller to control the position with force control was built. The mechanical impedance determines the relationship between the force acting on the object and its velocity. Mechanical admittance is defined as the inverse of the mechanical impedance (Jordan et al., 2015). The parameters of the admittance controller are inertia, damping and stiffness. The input value of the regulator is the force error signal $e_{F}$, and the output signal is the set velocity signal for the $V_{F}$ drive. Writing the output equation (1) in discrete form we get expression for the value $V_{F}$ of velocity for the subsequent runs of the control loop.

$$
V_{F}=\frac{e_{F}(k)-K \cdot T_{s} \cdot \sum_{i=0}^{k-1} V_{F}(i)+M \frac{V_{F}(k-1)}{T_{s}}}{\frac{M}{T_{s}}+K \cdot T_{s}+B}
$$

where: $M$ - inertia coefficient, B - damping factor, $\mathrm{K}$ - stiffness factor, $T s$ - sampling time.

a)
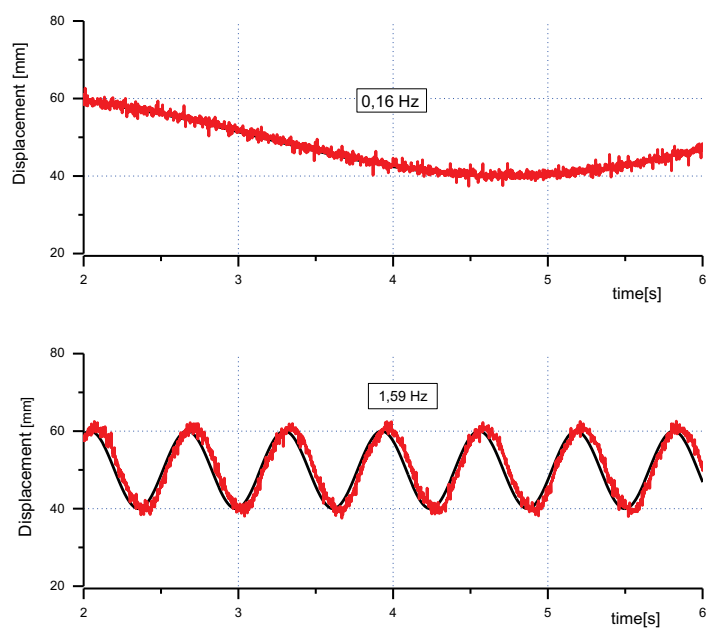

b)
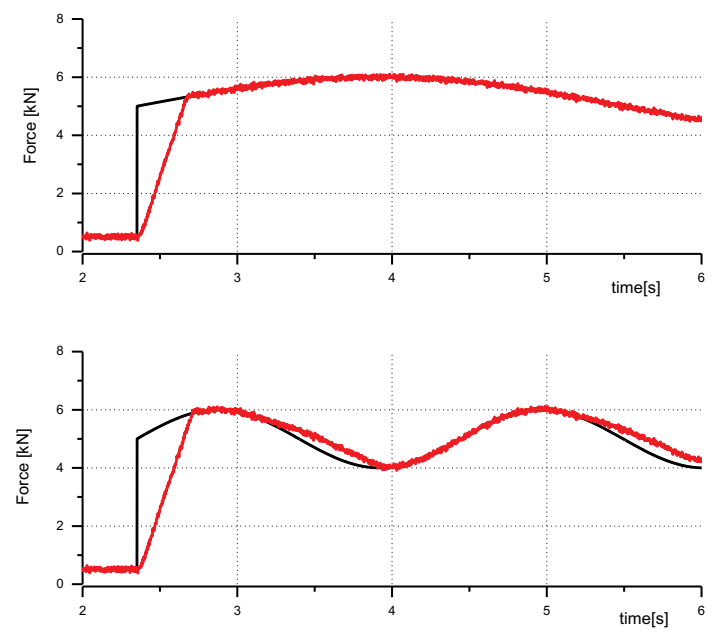

Fig. 4: Experimental results, according to the sinusoidal trajectory: a) displacement of the piston cylinder, b) tracking the desired force pressure 


\section{Conclusions}

The hydraulic servo actuator applications are particularly important to stabilize the position of machine elements that work for the whole range of displacements in which the characteristics of the propulsion system must be capable of obtaining stable positions at any point throughout the operating range. Along with control system they form servos with software or follower position control, velocity or strength. Attempts to use electro-hydraulic servo actuators, which would be competitive to electric servo motors, focus on the area of heavy-duty machines, which use high velocity and acceleration of movement. The controlled system can perform the following tasks: free movement of the slide and exerting a given force on the environment. An example of such behavior is a process where, in the initial phase, the servo-drive slide moves to the set position, after that the further movement can take place with the appropriate set force.

\section{References}

Blasiak, S., Takosoglu, J. E., Laski, P. A., Pietrala, D. S., Zwierzchowski, J., Bracha, G., ... Blasiak, M. (2017) Experimental and simulation flow rate analysis of the $3 / 2$ directional pneumatic valve, in: Exp. FLUID Mech. 2016 (EFM16 ) (ed. Dancova, P.), E D P SCIENCES, 17 AVE DU HOGGAR PARC D ACTIVITES COUTABOEUF BP 112, F-91944 CEDEX A, FRANCE, Vol. 143. doi:10.1051/epjconf/201714302008

Fernando, H. A., Marshall, J. A., Almqvist, H., and Larsson, J. (n.d.) Towards controlling bucket fill factor in robotic excavation by learning admittance control setpoints, . Retrieved from http://www.fsr.ethz.ch/papers/FSR_2017_paper_50.pdf

Hogan, N., and Buerger, S. P. (n.d.) Impedance and interaction control 19.1 introduction: controlling mechanical interaction, . Retrieved from http://summerschool.stiff-project.org/fileadmin/pdf/1804_C19.pdf

Jordan, M., Hofmann, U.-K., Rondak, I., Götze, M., Kluba, T., and Ipach, I. (2015) Brake response time is significantly impaired after total knee arthroplasty, American Journal of Physical Medicine \& Rehabilitation, 94, 9, pp. 665-676. doi:10.1097/PHM.0000000000000342

Kheowree, T., and Kuntanapreeda, S. (2015) Adaptive dynamic surface control of an electrohydraulic actuator with friction compensation, Asian Journal of Control, 17, 3, pp. 855-867. doi:10.1002/asjc.935

Lee, K.-H., and Newman, W. S. (2014) Natural admittance control of an electro-hydraulic humanoid robot, in: 2014 IEEE Int. Conf. Robot. Biomimetics (ROBIO 2014) IEEE, pp. 1100-1105. doi:10.1109/ROBIO.2014.7090479

Peng, X., Gong, G., Yang, H., Lou, H., Liao, X., and Wu, W. (2016) Novel electro-hydraulic position control system for primary mirror supporting system, Advances in Mechanical Engineering, 8, 5, pp. 168781401664794. doi:10.1177/1687814016647946

Rahmat, M., Md Rozali, S., and Abdul Wahab, N. (2010) Modeling and controller design of an electro-hydraulic actuator system, American Journal of Applied Sciences, 7, 8, pp. 1100-1108. Retrieved from http://thescipub.com/PDF/ajassp.2010.1100.1108.pdf

Richardson, R., Brown, M., Bhakta, B., and Levesley, M. (2005) Impedance control for a pneumatic robot-based around pole-placement, joint space controllers, Control Engineering Practice, 13, , pp. 291-303. doi:10.1016/j.conengprac.2004.03.011

Shaer, B., Kenné, J.-P., Kaddissi, C., and Mintsa, H. A. (2017) Real-time hybrid control of electrohydraulic active suspension, International Journal of Robust and Nonlinear Control, 27, 18, pp. 4968-4991. doi: $10.1002 /$ rnc.3842

Stefanski, T., and Zawarczynski, L. (2016) Analysis of inverter-fed drive of hydraulic pump in volumetric control system, in: 2016 21st Int. Conf. Methods Model. Autom. Robot. IEEE, pp. 146-151. doi:10.1109/MMAR.2016.7575123

Wos, P., and Dindorf, R. (2013) Adaptive control of the electro-hydraulic servo-system with external disturbances, Asian Journal of Control, 15, 4, pp. 1065-1080. doi:10.1002/asjc.602

Wos, P., and Dindorf, R. (2016) Practical parallel position-force controller for electro-hydraulic servo drive using on-line identification, International Journal of Dynamics and Control. doi:10.1007/s40435-014-0092-7

Yuan, H.-B., Na, H.-C., and Kim, Y.-B. (2017) System identification and robust position control for electrohydraulic servo system using hybrid model predictive control, Journal of Vibration and Control, pp. 107754631772141. doi:10.1177/1077546317721417 